\title{
APPLICATION OF COMPUTER FOR ANALYZING WORLD CO2 EMISSION
}

\author{
M. Kavoosi ${ }^{1}$, B.shafiee ${ }^{2}$ \\ ${ }^{1}$ Department of Computer Engineering, Izeh Branch, Islamic Azad University, Izeh, Iran \\ ${ }^{1}$ E-mail address: Hakavoosi@yahoo.com \\ ${ }^{2}$ E-mail address: Makavoosi@yahoo.com \\ "Corresponding author. Tel: +98 916 3917026; fax: +98 6115231068.
}

\begin{abstract}
Global climate change due to CO2 emissions is an issue of international concern that primarily attributed to fossil fuels. In this study, Genetic Algorithm (GA) is used for analyzing world CO2 emission based on the global energy consumption. Linear and non-linear forms of equations were developed to forecast $\mathrm{CO} 2$ emission using Genetic Algorithm (GA) based on the global oil, natural gas, coal, and primary energy consumption figures. The related data between 1980 and 2010 were used, partly for installing the models (finding candidates of best weighting factors for each model (1980-2003)) and partly for testing the models (2004-2010). Global CO2 emission is forecasted up to year 2030.
\end{abstract}

\section{KEYWORDS}

Genetic Algorithm (GA); Fossil fuels; Primary Energy; Carbon Dioxide Emission; Forecasting.

\section{INTRODUCTION}

The combustion of fossil fuels is the largest contributor to $\mathrm{CO} 2$ emissions. Research on emission trends and further forecasting their further values is important for adjusting energy policies, particularly those relative to low carbon (Lotalipur et al., 2010).

Many countries have started to develop climate policies but scenario studies indicate that greenhouse gas emissions are likely to increase in the future in most world regions (Dvoudpur and Sodagh Ahdi, 2006).

The outlook of GHGs emission shows the importance of the need for $\mathrm{CO} 2$ emission modeling. Several studies are presented to propose some models to investigate the causal relationships between energy consumption and $\mathrm{CO} 2$ emission (Lotalipur et al., 2010)

This study presents a Genetic Algorithm (GA) approach to forecast global CO2 emission due to energy consumption. 


\section{GENETIC ALGORITHM (GA)}

GAs encode candidate solutions as binary strings. Each string (chromosome) is built by chaining a number of sub-strings, each sub-string representing one of the candidate solution's features. Biological genes are in this case equivalent to the substrings encoding the parameters, while each binary digit can be related to the nucleotides composing the DNA. In most of the cases, one individual is fully described by a single bit-string, thus leading to the identification of the genotype with one single chromosome. Several other encoding procedures have been explored leading to a debate on the most appropriate choice. Holland (1975) showed that binary coding allows the maximum number of schemata to be processed per individual. On the other hand, the mapping to binary coding introduces Hamming cliffs onto the search surface. Moreover, nonbinary representations may be more natural for some problem domains and may reduce the computational burden of the search. The canonical binary-coded GA as described here is now rarely used for continuous function optimization as it has been shown that solutions are too easily disrupted (the Hamming cliff issue). Therefore researchers tend to use less disruptive coding such as Gray coding (Michalewicz, 1999).

Similarly to the other Evolutionary Algorithms (EAs), canonical GAs use generational replacement. Popular alternatives are elitism and steady-state replacement (Davis,1991). In the first case, the best solution (s) are directly copied into the new population while in the second case only a fraction of the population is replaced at each generation. Both variants aim to improve the preservation of good genetic material at the expense of a reduced search space exploration. A comparison between the behavior of generational and steady-state replacement is given in Syswerda (1991).

Individuals are selected for reproduction with a probability depending on their fitness. Canonical GAs allocate the mating probability of each individual proportionally to its fitness (proportional selection) and draw the parents set (mating pool) through the roulette wheel selection procedure (Goldberg, 1989). Other popular selection schemes are fitness ranking (Baker,1985) and tournament selection (Goldberg and Deb, 1991). For a comparison of selection procedure, the reader is referred to Goldberg and Deb (1991).

Crossover is the main search operator in GAs, creating offsprings by randomly mixing sections of the parental genome. The number of sections exchanged varies widely with the GA implementation. The most common crossover procedures are one-point crossover, two-point crossover and uniform crossover (Davis, 1991). In canonical GAs, a crossover probability is set for each couple. Couples not selected for recombination will generate two offsprings identical to the parents.

A small fraction of the offsprings are randomly selected to undergo genetic mutation. The mutation operator randomly picks a location from a bit-string and flips its contents. The importance of this operator in GAs is however secondary, and to the main aim of mutation is the preservation of the genetic diversity of the population.

GAs require the tuning of some parameters such as the mutation rate, crossover rate and replacement rate in the case of steady-state replacement. This task is often not trivial as the chosen values may strongly influence the search process (Grefenstette,1986; Schaffer et al.,1989). Moreover, the optimal value for the GA parameters may vary according to the evolution of the search process. For all these reasons, several adaptive schemes have been investigated. A survey of adaptation in GAs is given in (Hinterding et al.,1997; Back,1993) proposed an off-line tuning approach giving an optimal mutation rate schedule. Problem-specific operators are sometimes employed in addition to the canonical ones. The introduction of such operators results an increase 
International Journal of Computer Science, Engineering and Applications (IJCSEA) Vol.2, No.6, December 2012

in the search power of the algorithm but a loss of general applicability. This issue is analyzed in Michalewicz (1993). For more details about intelligent optimization techniques the readers are referred to (Asare et al., 2012a; Asare et al., 2012b; Asare et al., 2010).

\section{Problem definition}

In this study, global $\mathrm{CO} 2$ emission was projected based on the global oil, natural gas, coal and primary energy consumption using GA.

For this purpose, following forms of equations (Linear and exponential) are developed:

$$
\begin{aligned}
& \mathrm{CO}_{2_{\text {linear }}}=\mathrm{w}_{1} \mathrm{OIL}+\mathrm{w}_{2} \mathrm{NG}+\mathrm{w}_{3} \mathrm{COAL}+\mathrm{w}_{4} \mathrm{PE}+\mathrm{w}_{5} \\
& \mathrm{CO}_{2} \text { exp onential } \\
& =\mathrm{w}_{1} \mathrm{OIL}^{\mathrm{w} 2}+\mathrm{w}_{3} \mathrm{NG}^{\mathrm{w} 4}+\mathrm{w}_{5} \mathrm{COAL}^{\mathrm{w} 6}+\mathrm{w}_{7} \mathrm{PE}^{\mathrm{w} 8}+\mathrm{w}_{9}
\end{aligned}
$$

Where OIL, NG, COAL, PE are the global oil, natural gas, coal and primary energy consumptions and $\mathrm{w}_{\mathrm{i}}$ are the corresponding weighting factors.

The fitness function, $\mathrm{F}(\mathrm{x})$, takes the following form:

$\operatorname{Min} F(x)=\sum_{j=1}^{m}\left(E_{\text {actual }}-E_{\text {predicted }}\right)^{2}$

Where $\mathrm{E}_{\text {actual and }} \mathrm{E}_{\text {predicted }}$ are the actual and predicted values of global $\mathrm{CO} 2$ emission respectively, $\mathrm{m}$ is the number of observations.

The related data from 1980 to 2010 were used, partly for installing the models (finding candidates of best weighting factors for each model (1980-2003)) and partly for testing the models (20042010). The values of global oil, natural gas, coal, and primary energy consumption are obtained from Workbook (2011) and shown in Table 1.

$<<$ Table 1. The values of global oil, natural gas, coal, and primary energy consumption (Workbook; 2011).>>

\section{RESULTS AND DISCUSSION}

\subsection{Estimating Weighting Factors Values by GA}

In this section a code was developed in MATLAB 2008 (Math Works, Natick, MA) based on the GA and applied for finding optimal values of weighting factors regarding actual data (19802010). For this purpose, following stages were done:

(a) All input and output variables in Eqs. 1 and 2 were normalized in the $(0,1)$ range.

(b): The proposed algorithm (GA) was applied in order to determine corresponding weighting factors $\left(\mathrm{W}_{\mathrm{i}}\right.$ ) for each model. The related data from 1980 to 2003 were used in this stage. 
International Journal of Computer Science, Engineering and Applications (IJCSEA) Vol.2, No.6, December 2012

(c): The best results (optimal values of weighting parameters) for each model were chosen according to (b) and less average relative errors in testing period. The related data from 2004 to 2010 were used in this stage.

(d): Demand estimation models were proposed using the optimal values of weighting parameters. The GA models were performed using the following user-specified parameters:

Population size: 50

Crossover rate: 0.85

Mutation rate: 0.01

Maximum Generation: 200

In the linear and exponential forms of GA models, coefficients obtained are given below:

$$
\begin{aligned}
& \mathrm{GA}-\mathrm{CO}_{2}{ }_{\text {linear }}=0.2763 \mathrm{OIL}+0.0264 \mathrm{NG}+0.4218 \mathrm{COAL}+0.1973 \mathrm{PE}+0.0326 \\
& \mathrm{GA}-\mathrm{CO}_{2_{\text {exponential }}}=0.3427 \mathrm{OIL}^{2.0509}+0.9188 \mathrm{NG}^{0.9115}+0.0092 \mathrm{COAL}^{0.9096} \\
& -0.25644 \mathrm{PE}^{0.2827}+0.3597
\end{aligned}
$$

Table 2 shows the comparison between the Actual and estimated values of global $\mathrm{CO} 2$ emission on testing period.

$<<$ Table 2. Comparison between the Actual and estimated values of global $\mathrm{CO} 2$ emission on testing period (2004-2010) >>

As it can be seen in this table, the estimation models are in good agreement with the actual data but $\mathrm{GA}-\mathrm{CO}_{2}$ linear outperformed another presented model.

\subsection{Future Projection}

In order to use Eqs. (4) and (5) for future projections, each input variable (i.e. oil consumptionnatural gas consumption- coal consumption- primary energy consumption) should be forecasted in future time domain (2011-2030). To achieve this, the designed scenarios for future projection of each input variable remained the same which were developed by Bhreng et al. (2011a). The values of oil, natural gas, coal, and primary energy consumptions between 2011 and 2030 based on the designed scenario by Bhreng et al., (2011a) are shown in Table 3.

$<<$ Table 3. The values of designed scenario by Bhreng et al. (2011a) for oil, natural gas, coal, and primary energy consumptions between 2011 and 2030.>>.

Figure 1 shows the comparison between different projections for global $\mathrm{CO} 2$ emission.

<< Figure 1. Comparison between different projections for global CO2 emission. >

Table 4 shows the comparison of different projections for global $\mathrm{CO} 2$ emission.

$<<$ Table 4. Comparison of different projections for global CO2 emission (in million tones) up to 2030. $>$ 


\section{Conclusion}

This paper investigates the causal relationships among global carbon emission and energy consumption, using Genetic Algorithm (GA). 31 years data (1980-2010) were used for developing both forms (linear and exponential) of GA estimation models. Validations of models show that the estimation models are in good agreement with the observed data but GAlinear outperformed another developed model in this study. The results presented here provide helpful insight into energy system and $\mathrm{CO} 2$ emission control modeling. They are also instrumental to scholars and policy makers as a potential tool for developing energy plans.

Future work is focused on comparing the methods presented here with other available tools. Forecasting of $\mathrm{CO} 2$ emission can also be investigated with Particle Swarm Optimization, Artificial Bee Colony, Ant Colony, or other metaheuristic algorithm. The results of the different methods can be compared with the GA technique.

\section{ACKNOWLEDGMENTS}

The authors are grateful for the support provided for the present work by Izeh Branch, Islamic Azad University, Izeh, Iran.

\section{REFERENCES}

[1] Asare, E., Bhreng, M.A., and Ghanbarzad, A. 2010. Application of PSO (particle swarm optimization) and GA (genetic algorithm) techniques on demand estimation of oil in Iran. Energy 35: 5223-5229.

doi:10.1016/j.energy.2010.07.043.

[2] Asare, E., Bhreng, M.A., and Ghanbarzad, A., 2012a. Forecasting energy demand in Iran using genetic algorithm (GA) and particle swarm optimization (PSO) methods. Energy Sources, Part B: Economics, Planning, and Policy: in press.

[3] Asare, E., Bhreng, M.A. and Ghanbarzad, A., 2012b. Integration of Artificial Neural Networks and Particle Swarm Optimization to forecast world green energy consumption. Energy Sources, Part B: Economics, Planning, and Policy: in press.

[4] Bhreng, M.A., Asare, E., Ghanbarzad, A. 2011a. Using Bees Algorithm and Artificial Neural Network to Forecast World Carbon Dioxide Emission. Energy Sources, Part A: Recovery, Utilization, and Environmental Effects 33(19): 1747-1759.

doi: 10.1080/15567036.2010.493920.

[5] Bhreng, M.A., Asare, E., and Ghanbarzad, A. 2011b. Total Energy Demand Estimation in Iran Using Bees Algorithm. Energy Sources, Part B: Economics, Planning, and Policy 6(3): 294-303. doi: 10.1080/15567240903502594."

[6] Davis, L., 1991. Handbook of genetic algorithms. Van Nostrand Reinhold, New York.

[7] Dvoudpur, H., Sadegh Ahdi, M., 2006. The potential for greenhouse gases mitigation in household sector of Iran: cases of price reform/efficiency improvement and scenario for 2000-2010. Energy Policy 34: 40-49.

[8] EIA 2009. Annual Energy Outlook, 2009. DOE/EIA-0484-Reference Case Projections, Energy Information Administration (EIA). Washington, DC, USA.

[9] Grefenstette, J.J., 1986. Optimization of Control Parameters for Genetic Algorithms. Systems, Man and Cybernetics, IEEE Transactions on, 16(1), 122-128. 
International Journal of Computer Science, Engineering and Applications (IJCSEA) Vol.2, No.6, December 2012

[10] Goldberg, D.E., 1989. Genetic Algorithms in Search, Optimization and Machine Learning. Addison-Wesley Longman, Reading.

[11] Goldberg, D.E., Deb, K., 1991. A comparison of selection schemes used in genetic algorithms. G.J. ed. Foundations of Genetic Algorithms (FOGA 1), Rawlins, p.69-93.

[12] Hinterding, R., Michalewicz, Z., Eiben, A.E., 1997. Adaptation in evolutionary computation: a survey. Proc IEEE International Conference on Evolutionary Computation, p.65-69.

[13] Holland, J.H., 1975. Adaptations in Natural Artificial Systems. University of Michigan Press, Michigan.

[14] Lotalipur, M.R., Faleh, M.A., and Ahena, M. 2010. Economic growth, CO2 emissions, and fossil fuels consumption in Iran. Energy 35: 5115-5120.

[15] Michalewicz, Z., 1999. Genetic algorithms + data structures = evolution programs, 3rd rev. and extended ed. Springer-Verlag, Berlin.

[16] Pao, H.T. Tsai, C.M. 2011. Modeling and forecasting the CO2 emissions, energy consumption, and economic growth in Brazil. Energy 36: 2450-2458.

[17] Schaffer, J.D., Caruana, R.A., Eshelman, L.J., Das, R., 1989. A study of control parameters affecting online performance of genetic algorithms for function optimization. Proceedings of the Third international conference on Genetic algorithms, Morgan Kaufmann, San Francisco, CA, p.51-60.

[18] Syswerda, G., 1991. Reproduction in generational and steady state Genetic Algorithm. In: Ratlines, G. ed. Foundations of Genetic Algorithms. Morgan Kaufmann, Los Altos, CA, p.94-101.

[19] Workbook, 2009. Statistical Review of World Energy 2009. Available online at http://www.bp.com/statisticalreview.

\section{Figure Captions:}

Figure 1. Comparison between different projections for global $\mathrm{CO} 2$ emission.

\section{Table Captions:}

Table 1 . The values of global oil, natural gas, coal, and primary energy consumption (Workbook; 2011).

Table 2. Comparison between the Actual and estimated values of global $\mathrm{CO} 2$ emission on testing period (2004-2010) .

Table 3. The values of designed scenario by Bhreng et al. (2011a) for oil, natural gas, coal, and primary energy consumptions between 2011 and 2030.

Table 4. Comparison of different projections for global $\mathrm{CO} 2$ emission (in million tones) up to 2030 . 


\begin{tabular}{|c|c|c|c|c|c|}
\hline Year & $\begin{array}{l}\text { Oil } \\
\text { consumption } \\
(\text { Mtoe })^{\mathrm{a}}\end{array}$ & $\begin{array}{l}\text { NG } \\
\text { consumptio } \\
\text { n (Mtoe) }\end{array}$ & $\begin{array}{l}\text { Coal } \\
\text { consumption } \\
\text { (Mtoe) }\end{array}$ & $\begin{array}{l}\text { PE } \\
\text { consumptio } \\
\text { n (Mtoe) }\end{array}$ & $\begin{array}{l}\mathrm{CO}_{2} \\
\text { emission } \\
(\mathrm{Mt})^{\mathrm{b}}\end{array}$ \\
\hline 1980 & 2972.2 & 1296.9 & 1806.4 & 6624.0 & 19322.4 \\
\hline 1981 & 2863.0 & 1309.5 & 1820.6 & 6577.5 & 19073.2 \\
\hline 1982 & 2770.7 & 1312.5 & 1846.9 & 6548.4 & 18900.7 \\
\hline 1983 & 2748.3 & 1329.0 & 1897.7 & 6638.2 & 19072.1 \\
\hline 1984 & 2810.1 & 1440.0 & 1983.2 & 6960.2 & 19861.0 \\
\hline 1985 & 2804.7 & 1488.3 & 2056.0 & 7137.5 & 20246.7 \\
\hline 1986 & 2894.1 & 1503.6 & 2089.2 & 7307.5 & 20688.3 \\
\hline 1987 & 2946.8 & 1579.6 & 2169.0 & 7555.7 & 21344.5 \\
\hline 1988 & 3038.8 & 1654.9 & 2231.7 & 7833.5 & 22052.2 \\
\hline 1989 & 3093.0 & 1729.2 & 2251.2 & 8001.7 & 22470.2 \\
\hline 1990 & 3148.6 & 1769.5 & 2220.3 & 8108.7 & 22613.2 \\
\hline 1991 & 3148.2 & 1807.5 & 2196.4 & 8156.0 & 22606.5 \\
\hline 1992 & 3184.8 & 1817.9 & 2174.6 & 8187.6 & 22656.7 \\
\hline 1993 & 3158.0 & 1853.9 & 2187.6 & 8257.5 & 22710.6 \\
\hline 1994 & 3218.7 & 1865.4 & 2201.9 & 8357.6 & 22980.3 \\
\hline 1995 & 3271.3 & 1927.0 & 2256.2 & 8577.9 & 23501.7 \\
\hline 1996 & 3344.9 & 2020.5 & 2292.2 & 8809.5 & 24089.8 \\
\hline 1997 & 3432.2 & 2016.8 & 2301.8 & 8911.6 & 24387.1 \\
\hline 1998 & 3455.4 & 2050.3 & 2300.2 & 8986.6 & 24530.5 \\
\hline 1999 & 3526.0 & 2098.4 & 2316.0 & 9151.4 & 24922.7 \\
\hline 2000 & 3571.6 & 2176.2 & 2399.7 & 9382.4 & 25576.9 \\
\hline 2001 & 3597.2 & 2216.6 & 2412.4 & 9465.6 & 25800.8 \\
\hline 2002 & 3632.3 & 2275.6 & 2476.7 & 9651.8 & 26301.3 \\
\hline 2003 & 3707.4 & 2353.1 & 2677.3 & 9997.8 & 27508.7 \\
\hline 2004 & 3858.7 & 2431.8 & 2858.4 & 10482.0 & 28875.2 \\
\hline 2005 & 3908.5 & 2511.2 & 3012.9 & 10800.9 & 29826.1 \\
\hline 2006 & 3945.3 & 2565.6 & 3164.5 & 11087.8 & 30667.6 \\
\hline 2007 & 4007.3 & 2661.3 & 3305.6 & 11398.4 & 31641.2 \\
\hline 2008 & 3996.5 & 2731.4 & 3341.7 & 11535.8 & 31915.9 \\
\hline 2009 & 3908.7 & 2661.4 & 3305.6 & 11363.2 & 31338.8 \\
\hline 2010 & 4028.1 & 2858.1 & 3555.8 & 12002.4 & 33158.4 \\
\hline
\end{tabular}

a(Mtoe): Million tonne oil equivalent

$\mathrm{b}(\mathrm{Mt})$ : Million tonne 
International Journal of Computer Science, Engineering and Applications (IJCSEA) Vol.2, No.6, December 2012

Table 2. Comparison between the Actual and estimated values of global CO2 emission on testing period (20042010).

\begin{tabular}{lllllllll}
\hline $\begin{array}{l}\text { Years } \\
\text { Actual Data }\end{array}$ & 2004 & 2005 & 2006 & 2007 & 2008 & 2009 & 2010 & $\begin{array}{l}\text { Average } \\
-\end{array}$ \\
\hline GA-CO2 ${ }_{\text {exponential }}$ & 28875.2 & 29826.1 & 30667.6 & 31641.2 & 31915.9 & 31338.8 & 33158.4 & - \\
Relative error (\%) & 4.46 & 0.68 & 0.45 & 1.00 & 1.00 & 2.66 & 5.55 & 2.26 \\
GA-CO2 linear & 27586.2 & 29624.2 & 30530.8 & 31324.7 & 32233.9 & 32171.0 & 31317.7 & - \\
Relative error (\%) & 1.91 & 2.10 & 1.31 & 0.62 & 0.03 & 0.59 & 0.82 & 1.06 \\
\hline
\end{tabular}

Table 3. The values of designed scenario by Bhreng et al. (2011a) for oil, natural gas, coal, and primary energy consumptions between 2011 and 2030.

\begin{tabular}{lllll}
\hline Year & $\begin{array}{l}\text { Oil } \\
\text { consumption } \\
\text { (Mtoe) }\end{array}$ & $\begin{array}{l}\text { NG } \\
\text { consumption } \\
\text { (Mtoe) }\end{array}$ & $\begin{array}{l}\text { Coal } \\
\text { consumption } \\
\text { (Mtoe) }\end{array}$ & $\begin{array}{l}\text { PE } \\
\text { consumption } \\
\text { (Mtoe) }\end{array}$ \\
\hline 2011 & 4071.1 & 2888.1 & 3662.3 & 12206.0 \\
2012 & 4104.7 & 2952.9 & 3775.6 & 12455.5 \\
2013 & 4138.3 & 3017.6 & 3888.8 & 12704.9 \\
2014 & 4171.9 & 3082.4 & 4002.1 & 12954.4 \\
2015 & 4205.4 & 3147.2 & 4115.3 & 13203.8 \\
2016 & 4239.0 & 3211.9 & 4228.5 & 13453.2 \\
2017 & 4272.6 & 3276.7 & 4341.8 & 13702.7 \\
2018 & 4306.2 & 3341.4 & 4455.0 & 13952.1 \\
2019 & 4339.7 & 3406.2 & 4568.3 & 14201.6 \\
2020 & 4373.3 & 3470.9 & 4681.5 & 14451.0 \\
2021 & 4406.9 & 3535.7 & 4794.8 & 14700.5 \\
2022 & 4440.5 & 3600.5 & 4908.0 & 14949.9 \\
2023 & 4474.0 & 3665.2 & 5021.3 & 15199.3 \\
2024 & 4507.6 & 3730.0 & 5134.5 & 15448.8 \\
2025 & 4541.2 & 3794.7 & 5247.8 & 15698.2 \\
2026 & 4574.7 & 3859.5 & 5361.0 & 15947.7 \\
2027 & 4608.3 & 3924.3 & 5474.3 & 16197.1 \\
2028 & 4641.9 & 3989.0 & 5587.5 & 16446.6 \\
2029 & 4675.5 & 4053.8 & 5700.8 & 16696.0 \\
2030 & 4709.0 & 4118.5 & 5814.0 & 16945.4 \\
\hline
\end{tabular}


International Journal of Computer Science, Engineering and Applications (IJCSEA) Vol.2, No.6, December 2012

Table 4. Comparison between different projections for global CO2 emission (in million tons) up to 2030.

\begin{tabular}{llccc}
\hline \multirow{2}{*}{ Projection } & Year & & \\
& & & & \\
\cline { 2 - 5 } & 2015 & 2020 & 2025 & 2030 \\
\hline Present Study $\left(\mathrm{Co}_{2 \text { linear }}\right)$ & 35436.8 & 38674.4 & 41912.0 & 45149.6 \\
\hline Behrang et al (2011a) & 38637.1 & 44812.5 & 51765.3 & 59469.7 \\
\hline EIA (2009) & 33111 & 35428 & 37879 & 40385 \\
\hline
\end{tabular}

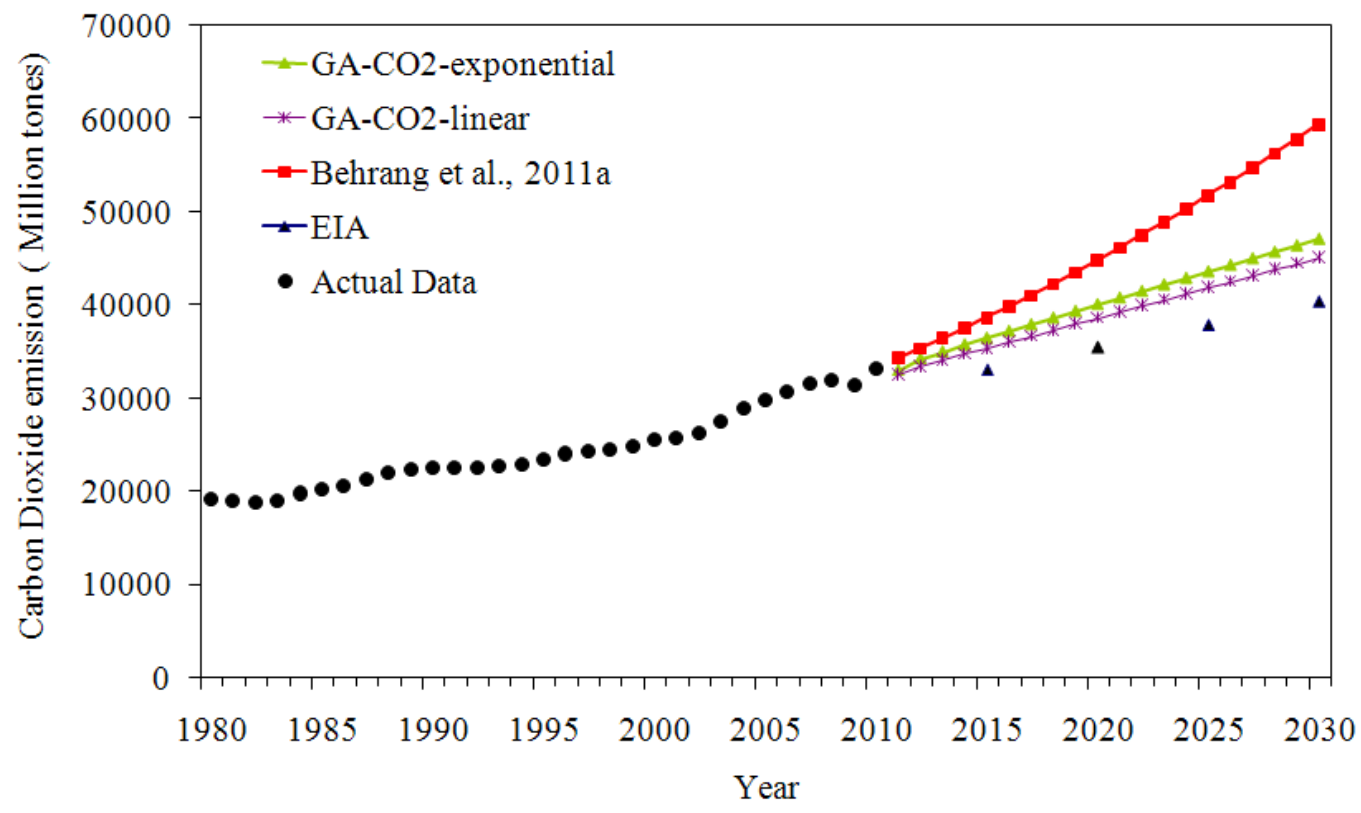

Figure 1. Comparison between different projections for global $\mathrm{CO} 2$ emission. 